\title{
Ontogeny of Single Nephron Filtration Distribution in Canine Puppies
}

\author{
NICK TAVANI. Jr., PHILIP CALCAGNO, STEVE ZIMMET, WALTER FLAMENBAUM, GILBERT \\ EISNER, and PEDRO JOSE \\ Departments of Pediatrics, Phisiologi: and Biophysics. Georgetown University Hospital. Washington. D. (.. and \\ Department of Medicine. Veterans Administration Hospital. Boston. Massachusetts. USA
}

\section{Summary}

The ontogeny of single nephron filtration distribution was studad in 29 canine puppies two hr to 42 days old using the $I^{14} \mathrm{Cl}$ errocyanide method as modified by Coehlo (9). The ratio of ${ }^{14} \mathrm{C}$ ounts in outer cortical nephrons (OC) to counts in juxtamedullary ephrons (JM) were plotted against age for each puppy. This ratio $O(: J M)$ provided an index for comparing the single nephron lomerular filtration between regions. A four-fold increase in $\mathrm{OC}$ : $M$ occurred from two days to four wk. The youngest puppy, two ir old, showed a ratio of zero because no counts were detected in C at that age.

The most rapid increase occurred in the first 8 days of life. By he fourth wk, the mean $\mathrm{OC}: \mathrm{JM}$ ratio was $0.72 \pm 0.06$, approaching alues reported by other laboratories for adult dogs. In contrast to ige-related changes in OC:JM ratio, the ratio of middle cortical o.JM counts showed no age-related increase. Cortical blood flow listribution was determined by the microsphere method. The ratio if blood flow to outer and inner cortex increased from 0.43 at onelalf a day to a mean of 2.93 after one wk. The ratio of OC:JM ingle nephron filtration to $O C$ /inner cortical nephron renal blood low was 0.36 from 3 days to 26 days $(n=12)$ and did not change ignificantly with age, indicating that changes in zonal filtration natched the alterations in cortical blood fow distribution.

\section{Speculation}

These studies suggest that although systemic arterial pressure changes probably play a role in the increasing single nephron filtration in the outer cortex of the maturing puppy, it is likely that plasma flow is a governing factor.

In the kidney of the neonate, the juxtamedullary nephrons (JM) are more fully developed than nephrons located in the outer cortical areas; maturation proceeds from the inner cortex (IC) to the outer cortex (OC) (13, 26, 27). A similar centrifugal development has been described for renal blood flow (RBF) distribution $(2,6,8,19,24)$. In the dog, a relatively greater IC flow is seen at birth and during the first 2 to 3 wk of life. After $3 \mathrm{wk}$, this pattern of intracortical blood flow distribution is similar to that in the adult dog. By 10 to 12 wk of age. RBF and the cortical/medullary distribution are like adult patterns (8). Available studies suggest that the maturation of filtration may proceed in a centrifugal fashion similar to that described for $\operatorname{RBF}(3,11,12,30)$; however. there is less documentation available

In the rat. Aperia $e t$ al. (4) noted a sharp increase in superficial single-nephron filtration rate per g kidney weight between 17 and 30) days. Spitzer and Brandis (28) suggested that in the guinea pig during the first two wk of life, glomerular filtration was due mainly to JM. Thereafter, the increase in superficial nephron filtration accounted for most of the increase in total kidney filtration. In the dog. Horster and Valtin (15) reported an increasing contribution of superficial nephron filtration to total kidney filtration during the first four months of postnatal life. Glomerulogenesis might account for these increases in filtration because it has been demonstrated to continue in the OC for wk after birth in certain species including rats and dogs (16).

For some species, the pattern of glomerular filtration distribution during the first few days of life has been studied by comparing single nephron filtration rate in superficial nephrons with total kidney filtration. In the neonatal dog, single nephron filtration rates in the $O C$ cannot be measured by micropuncture techniques because of the low proximal tubular flow in the first 3 wk of life.

The ontogeny of single nephron filtration distribution was studied in canine puppies two hr to 42 days old using the $\left[{ }^{1.4} \mathrm{C}\right]$ ferrocyanide method $(10,14)$ as modified by Coehlo et al. (9). This method allows a direct quantitation of single nephron filtration in neonatal animals where other methods are technically not feasible. The results indicate that single nephron filtration is greatest in the $\mathrm{JM}$ irrespective of age. The ratio of $O C$ to $\mathrm{JM}$ filtration is lowest in the newborn period and increases progressively to reach adult levels by the fourth wk of life. The change in filtration distribution with maturation appears to be due in part to the rise in perfusion pressure with age. but intrarenal factors are implicated as well.

\section{MATERIALS AND METHODS}

Mongrel puppies, aged $2 \mathrm{hr}$ to 42 days were studied. Puppies remained with the litter until one hr before the experiment. Food intake was controlled by keeping the litter size relatively constant during the wk the siblings were studied. Each mother nursed about three to four siblings.

Prior to the experiment the puppies were weighed, fasted for one $\mathrm{hr}$, and anesthetized with pentobarbital $(12$ to $22 \mathrm{mg} / \mathrm{kg}$ depending upon age). Body temperature was maintained at $37^{\circ} \mathrm{C}$ on a thermoregulated small animal surgical table. After tracheostomy, one femoral artery was catheterized to the aortic root for the injection of microspheres. The other femoral artery was used to monitor blood pressure. The right external jugular vein was catheterized for infusion of ferrocyanide. and the left jugular vein was catheterized for fluid infusion. Urine was collected from both ureters. Urine and surgical fluid losses were replaced volume for volume with electrolyte solution containing $25 \mathrm{mEq}$ sodium per liter and $20 \mathrm{mEq}$ potassium per liter. The left kidney was carefully exposed retroperitoneally. and the renal vessels were loosely tied. The incision was closed with clamps and kept moist. A period of $60 \mathrm{~min}$ was allowed for postsurgical recovery.

Three 10-min urine samples were collected after surgical recovery. The animals then received an infusion of microspheres or $I^{14} \mathrm{C} \mid$ ferrocyanide or microspheres followed by $\left[{ }^{14} \mathrm{C}\right]$ ferrocyanide. Microspheres, $15 \pm 5 \mu \mathrm{m}$ in diameter (New England Nuclear: 0.5 $\mathrm{ml}{ }^{1+11} \mathrm{Ce}$ or $0.3 \mathrm{ml}{ }^{\text {Ni5 }} \mathrm{Sr}$ randomly assigned) were infused for $30 \mathrm{sec}$ for determination of cortical blood flow distribution. $\left[{ }^{1 .} \mathrm{C}\right] \mathrm{FeCN}$ 125 to $250 \mu \mathrm{Ci}$ (New England Nuclear. Boston, MA) in $0.5 \mathrm{ml}$ fresh $10 \%$ FeCN solution was then infused for 15 to $18 \mathrm{sec}$ during which time arterial blood was sampled for hematocrit and $\left[{ }^{14} \mathrm{C}\right]$ 
ferrocyanide concentration. No significant change in blood pressure was observed. The left kidney was then immediately ligated, removed, and quick frozen in an acetone dry ice bath. Right kidneys were later removed in all animals for weighing and microsphere analysis.

The frozen left kidney was fractured into two sections using a sharp knife. Rectangular pieces of cortex from each kidney were divided into outer and inner sections in a $2: 1$ weight ratio. Triplicate samples for each kidney were weighed and counted for gamma activity. The ratio of counts/g of OC to counts/g of IC served as an index of RBF distribution (8).

The remaining left kidney was fragmented, placed into a chilled vial of $20 \mathrm{ml} \mathrm{FeCl}$ solution. and stored at $-20^{\circ} \mathrm{C}$ for 19 to $22 \mathrm{hr}$. The tissue was transferred to $100 \mathrm{ml}$ Erlenmeyer flasks, washed. and macerated in $20 \% \mathrm{HCl}$ at $41^{\circ} \mathrm{C}$ for $6 \mathrm{hr}$. The samples were washed and stored in distilled water at $4^{\circ} \mathrm{C}$.

Individual nephrons were teased out with fine needles (Circon Microsurgical) under a remote-controlled. fiber optics-illuminated dissecting microscope (Unislide Velmex A 4000). Each nephron was dissected up to the pars recta (in some cases to the descending loop of Henle). Nephrons dissected from the surface of the kidney were designated as OC. Those closest to the arcuate arteries were designated as $\mathrm{JM}$. The region between represented the middle cortical nephrons (MC). At least 10 nephrons were dissected from each region of each kidney.

Isolated nephrons were placed on glass cover slip fragments and transferred to a Wild Hereburg microscope set up for camera lucida tracing. The nephron was traced, and the dye front was recorded. Prussian blue precipitate appeared in the glomeruli and along the tubule to the dye front. Nephrons were macerated overnight in $0.5 \mathrm{ml}$ nitric acid. Scintillation fluid (2:1 toluene: Triton X-100 solution containing $5 \mathrm{~g}$ of Omnifluor from New England Nuclear) was then added, and the vials were counted for beta activity. Each vial contained from three to six nephrons. Only counts more than twice background were accepted; as Kuruda suggests, when radioactivity in dissected nephrons is low, background radiation may make interpretation difficult (23).

The activity in the tubular portions distal to the dye front was judged to represent extraluminal contamination, and this amount was subsequently subtracted from each tubular count. The extraluminal contamination represented $10^{\prime \prime}$ of total counts in the JM and $15 \%$ in $O C$. To determine the influence of glomerular size on nephron counts, some nephrons were divided into three portions: glomerulus, tubule proximal to the dye front. and tubule distal to the dye front. Glomerular activity represented $36 \%$ of total tubular counts in the $\mathrm{OC}$ and $38 \%$ in the JM. These data indicate that extraluminal contamination and glomerular tuft contribution were similar in $O C$ and $\mathrm{JM}$.

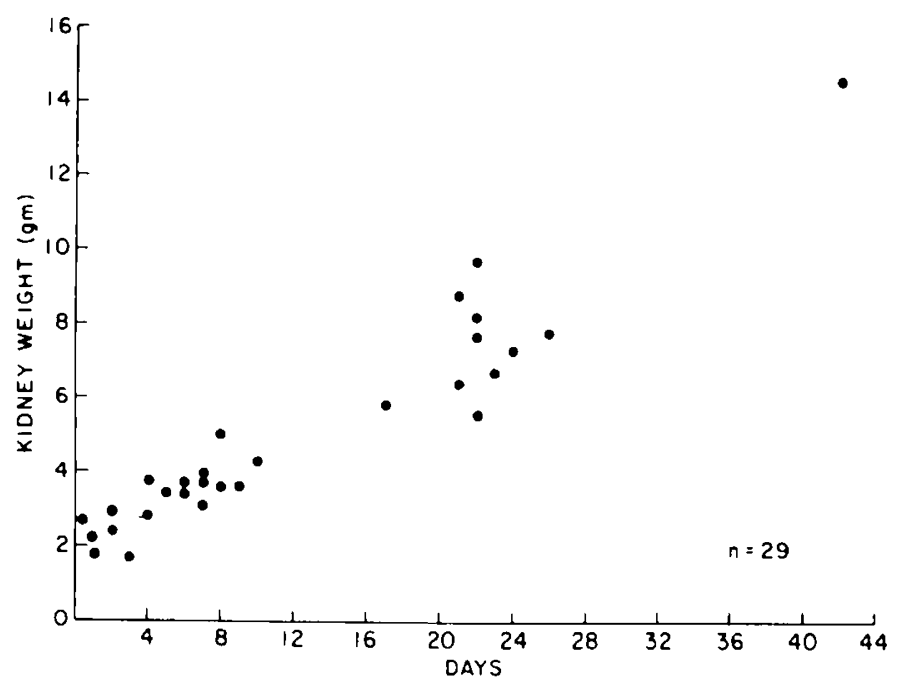

Fig. 1. Age of animals in days plotted against kidney weight. $r=0.96$; $P<0.01, \mathrm{Yc}=0.268 \times+1.80$.

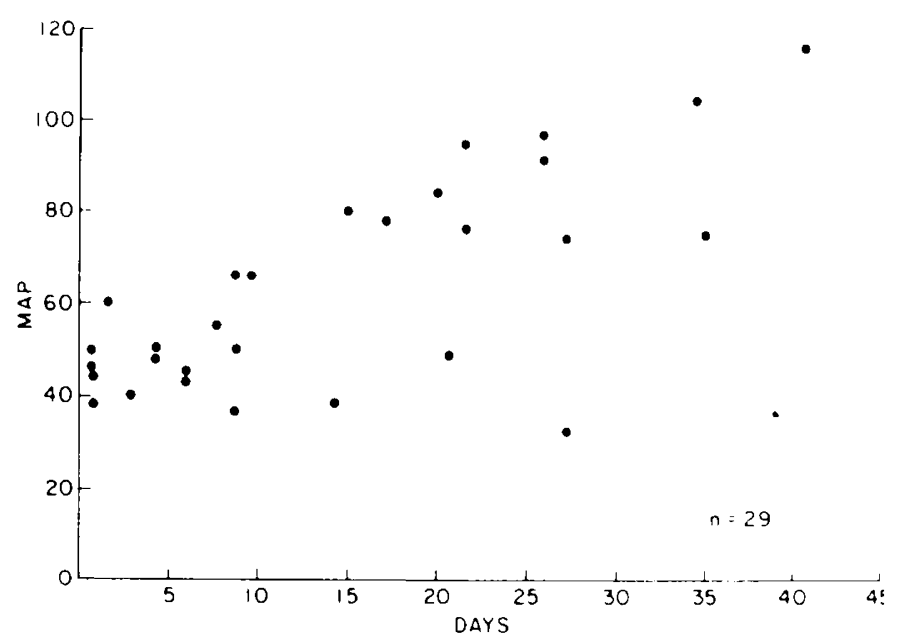

Fig. 2. Age of animals in days is plotted against MAP in $\mathrm{mm} \mathrm{Hg.} r=$ 0.73: $P<0.01: Y_{C}=1.43 \times+42.40$.

Statistical analysis was performed using the Student $t$ test for group data and for slopes. Linear regression was determined by the least-squares method. Values are given as mean \pm S.E. $P<$ 0.05 was considered significant.

\section{RESULTS}

\section{BOIDY WEI(IHT AND KIIDNEY WEI(IHT}

Body weight increased linearly with age. Wet kidney weight also showed a linear increase with age (Fig. 1$)(r=0.96 ; p<0.01$ $Y c=0.268 X+1.80)$ and remained a constant proportion $(0.80$ $\pm .01 \%)$ of body weight throughout the growth period.

\section{MLAN ARTERIAL. PRESSURE.}

There was a 2.6 -fold increase in mean arterial blood pressure (MAP) over the first $6 \mathrm{wk}$ of neonatal maturation from $44 \mathrm{~mm} \mathrm{(3}$ days) to $116 \mathrm{~mm} \mathrm{Hg}$ (6 wk) (Fig. 2). As a group $(n=29)$, the rise in pressure was linear with age $(r=0.73 ; p<0.01: \mathrm{Yc}=1.43 \mathrm{X}$ +42.40 ). In the first wk of life. MAP was not age related.

\section{IDSTRIBL:TION OF SINGILE NEPHIRON FIITRATION}

OC in all puppies studied $(n=29)$ had a mean of $11.6 \pm 1.2$ $\mathrm{cpm}$ whereas JM had a mean of $23.4 \pm 2.6 \mathrm{cpm}$. The ratio of ${ }^{14} \mathrm{C}$ counts in the $O C$ to counts in the JM are plotted against age for each puppy (Fig. 3). This ratio (OC:JM) provides an index for comparing the single nephron glomerular filtration rate (SNGFR) between regions. The youngest puppy, $2 \mathrm{hr}$ old, showed a ratio of zero because no counts were detected in the $O C$ at this early stage. The mean OC:JM in the first 2 days of life was $0.17 \pm 0.07$; by 4 wk of age, the mean was $0.72 \pm 0.06$, a four-fold increase. The most rapid increase in OC: $\mathrm{JM}$ occurred in the first 7 days of life and plateaued at the second to third wk. A slower rise occurs by the fourth wk, at which time the mean OC:JM ratio was $0.72 \pm$ 0.06 , approaching values reported by other laboratories for adult dogs (9). The regression could best be described as a fourth order polynomial, assuming that an asymtote of 0.8 could be achieved $\mathrm{YC}=0.092 \pm 0.0982 \mathrm{X}-8.872\left(10^{3}\right) \mathrm{X}^{2}+3.475\left(10^{-4}\right) \mathrm{X}^{3}-$ $\left.4.434\left(10^{\circ}\right) X^{4}\right]$. In contrast to age-related changes in OC:JM ratio, the ratio of middle cortical to juxtamedullary counts $(0.064$ \pm 0.05 ) showed no age-related increase. Figure 4 shows $O C: J M$ as a function of MAP $(r=0.60: P<0.01 ; \mathrm{Yc}=0.006 \mathrm{X}+0.17)$ Urine flow failed to correlate with single nephron glomerular filtration (SNGF) in our studies.

\section{DISTRIBUTION OF: (ORTICAL BLOOD FI.OW}

Studies were performed in 17 animals one-half day to 22 days old. Blood flow per $\mathrm{g}$ of tissue was higher in OC in $83 \%$ of cases 
lespite the fact that single nephron filtration was consistently igher in JM. The ratio of counts/g of OC to counts/g of IC ncreased from 0.43 at one-half day to $1.43 \pm 0.22(n=11)$ in the irst wk of life to $2.93 \pm 1.04(n=6)$ beyond one wk $(P<0.05)$. The increase of this ratio with age can be described as a linear unction $r=0.77: P<0.0 \mathrm{I}: \mathrm{Yc}=0.24 \mathrm{X}+0.29$. The fewer lumbers of puppies beyond one wk of age limited our comparing lopes of OC:JM SNGFR and OC:IC RBF.

\section{DISTRIBUTION OF RBF IERSLS DISTRIBUTION OF SING NEPHRON FII.TRATION}

In 9 puppies, both blood flow and single nephron filtration were measured in the same animal. Eight animals were 2 to 9 days sld: one was 22 days old. Because single glomerular blood flow was not determined, values for filtration fraction per nephron are lot available. The ratio of OC:JM SNGF to OC:IC RBF, however. may serve as an index of this function. This ratio of $0.36 \pm 0.06$ S.E.) did not change significantly with age $(r=0.28 ; P>0.05)$, indicating that the changes in zonal filtration matched the alterations in cortical blood flow distribution.

\section{DISC USSION}

These studies directly demonstrate for the first time a centrifugal pattern of maturation of glomerular filtration in the immediate neonatal period. In the first 3 days of postnatal life, the filtration rate of $J M$ was four and one-half times greater than that in the sutermost cortical nephrons. The greatest increase in filtration rate of outer nephrons occurred in the first wk of life. Thereafter.

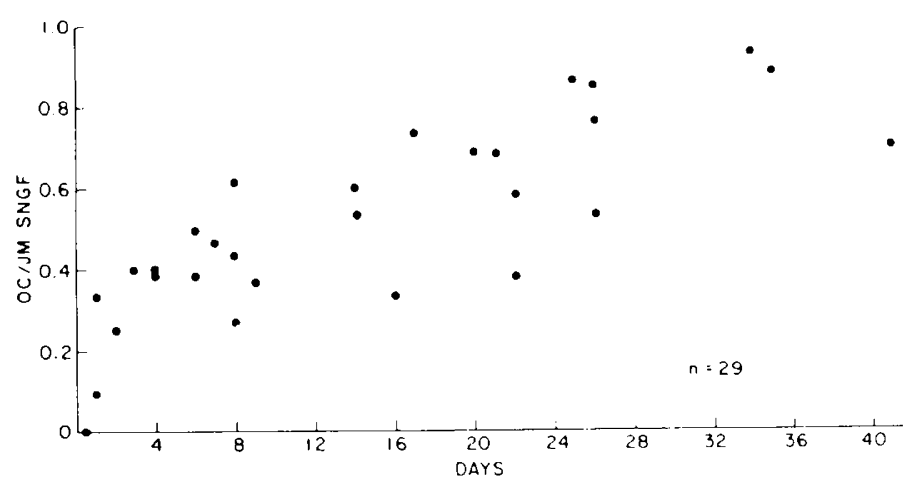

Fig. 3. Age of animals in days is plotted against the ratio of $O C^{\prime}$ to $J M$ SNGi: $r=0.81: P 0.01: Y c=0.02 \times+0.27: n=29$. This ratio was determined by comparing the $\left.\right|^{14} \mathrm{C} \mid \mathrm{ferrocy}$ anide counts in dissected $O C$ and $\mathbf{J M}$

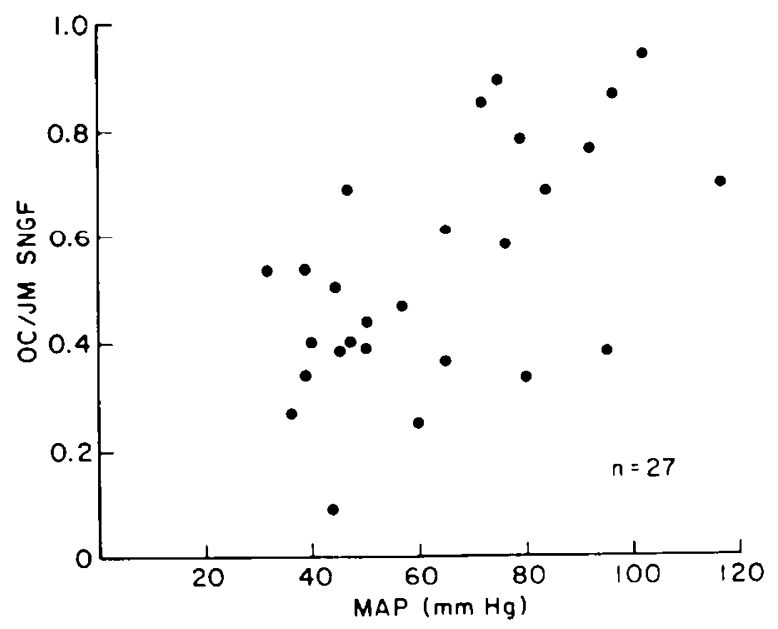

Fig. 4. O(:JM SNGF is plotted against MAP, $r=0.60): P<0.01 ; \mathrm{Yc}$ $=0.006 x+0.17$ a slower rise of OC:JM ratio occurred, and by the fourth wk. values similar to those reported for adult dogs were achieved.

A finely graded change in SNGFR from one cortical region to the adjacent concentric region, if verified, would support the view of an infinitely partitioned centrifugal distribution of filtration function as postulated by Spitzer and Brandis (28). A comparison of such adjacent regions with nearly the same $S N G F R$ would presumably turn up SNGFR ratios that were nearly equal to one. Only in nonadjacent regions, such as $O C$ and IC would the regional heterogeneity be significant enough to give a ratio different from one.

We failed to show a difference between either cortical extreme and the adjacent $\mathrm{MC}$ as shown by the ratios $\mathrm{OC}: J \mathrm{M}$ and $\mathrm{MC}: J \mathrm{M}$. If the middle region were indeed heterogeneous, then sampling error could mask differences by cancelling out higher counts from nephrons randomly sampled near the juxtamedullary region with lower counts likewise obtained near the OC. Hence. the $M C$ would appear to be homogenous due to this sampling. An alternate explanation may be that the outer and juxtamedullary cortical regions define two distinct and unique populations. A heterogeneous intermediate region would contain elements of both regions.

The greater increase in OC over JM SNGF with age may be due to any of the factors which can affect filtration. These include glomerular surface area and permeability, hydrostatic forces, and renal plasma flow. It is unlikely that there is a greater increase in glomerular capillary surface area in OC compared to IC glomeruli because John (18) has shown that the ratio of OC to IC glomerular capillary surface area decreases at three wk, at a time when $O C /$ JM SNGF is increasing.

('hanges in glomerular permeability coefficient with age have been evaluated in humans and rats $(5,7)$. In the human, Arturson et al. (5). using dextran tracers, suggested that glomerular permeability increased with age. An increase in glomerular permeability with age has also been reported in Munich-Wistar rats (29). Recently, however, in the same species, Ichikawa and Brenner (17) suggested that glomerular ultrafiltration coefficient is not a factor limiting SNGFR in the neonatal rat because filtration equilibrium exists. However, because filtration equilibrium has not been definitely shown in dogs, this possibility must be considered.

Factors determining glomerular filtration rate in maturing $\mathrm{Mu}$ nich-Wistar rats have recently been studied by micropuncture techniques (17.29). Between 40 and 140 days of life, although afferent and efferent arteriolar resistances were higher in the younger rats, glomerular capsular pressure was unchanged. Because proximal tubular hydrostatic pressure was also constant during growth, it was concluded that changes in hydrostatic forces did not contribute to the increase in SNGFR with growth. However, it should be noted that in these rats systemic arterial pressure was also constant during the period of study. Allison et al. (1) studied rats less than 30 days old and reported that glomerular capillary pressure (sum of stop flow tubular pressure and arteriolar oncotic pressure) was lower than in adult rats. Studies in the neonatal guinea pig ( $12 \mathrm{hr}$ to 49 days) have also shown that glomerular capsular pressure (indirect method) increased with age (28).

In dogs during the first three wh of life, an increase in mean systemic arterial pressure occurs, and positive correlation between glomerular filtration rate and systemic arterial pressure has been demonstrated $(15,20)$. In our studies in the first wk of life, OC:JM SNGF increased significantly, whereas MAP remained constant. Thereafter, age-related rises in both OC:JM SNGF and MAP were noted. When OC:JM was plotted as a function of mean systemic pressure, a regression of 0.60 was obtained. Such a positive correlation indicates that the centrifugal pattern of development of SNGFR could be related in part to the rise in mean systemic pressure. As shown in Allison's study (1), although arterial blood pressure was correlated with SNGFR, it did not correlate with hydrostatic pressure in efferent arterioles, pointing out the need for direct measurements of glomerular dynamics if firm correlations are to be drawn. 
Current data indicate absence of filtration equilibrium in the adult dog with normal perfusion pressures $(22,25)$. If this is the case in the puppy as well, then changes in age-related permeability may well play an important role in the increasing SNGFR noted. However, in adult dogs. when perfusion pressure is diminished. filtration equilibrium becomes evident (21). Inasmuch as we are dealing with a low-pressure system in the puppy, it is possible that filtration equilibrium exists in this state.

In our studies, the changes in RBF distribution with age parallel the changes in zonal SNGFR. The centrifugal maturation of renal cortical blood flow has previously been documented by Jose et al. (19). Olbing et al. (24), and Aschinberg et al. (6). Although filtration fraction per nephron could not be calculated from these studies, the ratio of SNGFR OC:JM to OC:IC flow remained constant with age. Thus, the changes in SNGFR distribution with age may be secondary to concomitant alterations in cortical blood flow distribution and increases in glomerular plasma flow. Aperia and Herin (4), Ichikawa and Brenner (15) and Tucker and Blantz. (29) have previously indicated the importance of plasma flow in dictating changes in glomerular filtration in the maturing rat.

In conclusion, these studies suggest that although systemic arterial pressure changes probably play a role in the increasing SNGF noted with maturation in the puppy, it is likely that plasma flow is a governing factor, and a role for changes in permeability cannot currently be excluded.

\section{REFEREN(ES ANI) NOTES}

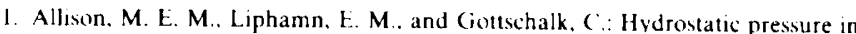
the rat kidney. Am. J. Physiol.. 223: 975 (1972).

2. Aperia. A.. Broberger, O.. Herin. P.. and Joelsson. 1.: Renal hemodynamics in the perinatal period: a study in lambs. Acta Physiol. Scand.. 44: 261 (1977)

3. Aperia, A. Broberger, O., and Herin. P.: Maturational changes in glomerula perfusion rate and glomerular filtration rate in lambs. Pediatr. Res.. $8: 758$ (1974)

4. Aperia. A.. and Herin. P.: Development of glomerular perfusion rate and nephron filtration rate in rats 17 60 days old. Am. J. Physiol.. 228: 1319 (1975).

5. Arturson. G.. Grath. T.. and Grotte, G.: Human glomerular membrane porosity and filtration pressure: dextran clearance data analyzed by theoretical models (lin. Sci. (Oxf.). 41): 137 (1971).

6. Aschinherg, L. C.. Goldsmith, D. L.. Olbing. H.. Hardy. M.. Spitzer. A.. Edelmann. C. M.. and Blaufox. M. D.: Neonatal changes in renal blood flow distrihution in puppies. Am J Physiol. 2.25: 1.453 (1975)

7. Bergelin. I. S. S... and Karlsson, B. W.: Functional structure of the glomerular filtration harrier and the proximal tubuli in the developing foetal and neonatal guinea pig. Anat. Embryol.. 145: 223 (1975).

8. Calcagno, P. L.. and Jose, P. A.: Maturation of renal blood flow. Proceedings 5th International Congress of Nephrology Mexico, 1: 21 (1972).

9. Coehlo, J. B.. Chien. K. C. H., and Bradley. S. F.: Measurement of single nephron filtration rate without micropuncture. Am. J. Physiol.. 223: 832 (1972)

10. deRouffignac, $C_{\text {., }}$ and Bonvalent. J. P.: Use of sodium ferrocyanide as glomerula indicator to study the functional heterogeneity of nephrons. Yale J. Biol. Med. 4. $243(1972)$
11. JeRouffignac, ( ... and Monnens, L.: Functional and morphologic maturation superticial and juxtamedullary nephrons in the rat. J. Physiol. (Lond.). If 119 (1976).

12. Dlouha. H., Bibr, B., Jezek. J.. and Zicha. J.: Single nephron filtration rate rat of superficial, intercortical and juxtamedullary nephrons in rats during dev opment. Ptlugers Arch. Eur. J. Physiol., 336: 277 (1976).

13. Fetterman, (3. H., Shoplock. N. A.. Philipp. F. J.. and (iregg. H. S.: The grow and maturation of human glomeruli and proximal convolutions from term adulthood: studies by microdissection. Pediatrics, 35: 601 (1976).

14. Hanssen. O. E.: A histochemical method for evaluation of excreted ferrocyani in isolated tubules of the mouse kidney. Acta Pathol Microbiol Scand... 363 (1958).

15. Horster, M.. and Valtin. H.: Postnatal development of renal function. Micr puncture and clearance studies in the dog. J. (Cin. Invest.. 5t): 779 (1971)

16. Horster. M.. Kember. B., and Valtin. H.: Intracortical distribution of numb and volume of glomeruli during postnatal maturation in the dog. J. Cli Invest.. 50): $796(1971)$

17. Ichikawa. T.. and Brenner. B. M.: Factors limiting glomerular filtration rate the immature rat. Pediatr. Res.. 1?:542 (1978).

1X. John. E.. (ioldsmith. D. L.. Edelmann. (. M., and Spitzer. A.: (jlomerul capillary volume and surface area during ontogeny. Pediatr. Res. Abstrac 11: $552(1977)$

19. Jose. P. A.. Logan. A. G.. Slotkoff, L. M.. Lilientield, L. S., Calcagno, P. L., at Eisner. (;. M.: Intrarenal blood flow distribution in canine puppies. Pedia Res.. 5: 335 ( 1971 )

20. Kleinmann. L. I., and Reuter. J. H.: Maturation of glomerular blood fl distribution in the newborn dog. J. Physiol. (I.ond.). 28: 91 (1973)

21. Knox. F. ( ..: (personal communication)

22. Knox. F. (j.. ('uche, J. L.. Ott, E.. Diaz-Buxo, J. A., and Marchand, ( Regulation of glomerular filtration and proximal tubule reabsorption. (i) Res.. 3o (Suppl. 1): 107 (1975).

23. Kuroda. S. Havashi, J., (iato. M.. Ino, Y.. Inamoto. H.. Aizawa, K., and Wad T.: A basic study of the Hanssen technique for evaluation of single nephr. glomerular filtration rate. Jpn. Circ. J., 4(t): 1261 (1976).

24. Olhing. H., Blaufox. M. D.. Aschinberg, 1.. A.. Silkalns, (;. I., Bernstein. Spitzer. A.. and Edelmann. F. M.: Postnatal changes in renal glomerular blor flow distribution in puppies. J. (lin. Invest. 52: 2885 (1973).

25. Ott. (. E... Marchand, (i. R.. Diaz-Buxo. J. A.. and Knox. F. (;.: Determinan of glomerular filtration rate in the dog. Am. J. Physiol.. 231: 235 (1976)

26. Potter. E. L.: Normal and abnormal development of the kidney. (Year Box Medical Publishers, (hicago, 1972).

27. Speller. A. M., and Moffat, D. B.: Tubulo-vascular relationships in the developi kidney. J. Anat. 123:487 (1977).

28. Spitzer. A.. and Brandis. M.: Functional and morphologic maturation of supe ficial nephrons: relationship to total kidney function. J. Clin. Invest. 53: 27 (1974).

29. Tucker. B. J., and Blantz. R. (. Factors determining superticial nephron tiltratic in the mature growing rat. Am. J. Physiol. 232: F47 (1977).

30. Zink. H., and Horster, M.: Maturation of diluting capacity in loop of Henle of $\mathrm{r}$ : superficial nephrons. Am. J. Physiol. 233: F519 (1977).

3 Presented in part at the Amnual Mectung of the American Sixtety of Nephrolog Washington. D. C 1976

32. The authors would like to acknowledge the secretarial assistance of (aroly Patterson.

33. Requests for reprints should he addressed to: Dr. Pedro A. Jose. Department Pediatric Nephrology. Georgetown University Hospital, I Y Bless Bldg.. 381 Reservoir Rd. N.W. Washington. D. C. $2(x) 07$ (USA)

34. This research was supported in part by a grant to Dr. P. A. Jose from th American Heart Association. National Capital Affiliate.

35. Received for publication March 26, 1979.

36. Accepted for publication August 13. 1974 